\title{
Interventions to improve patients' compliance with therapies aimed at lowering glycated hemoglobin (HbA1c) in type 1 diabetes: systematic review and meta-analyses of randomized controlled clinical trials of psychological, telecare, and educational interventions
}

\author{
Luciana Verçoza Viana ${ }^{1 *}$, Marilia Brito Gomes ${ }^{2}$, Lenita Zajdenverg ${ }^{3}$, Elizabeth Joao Pavin ${ }^{4}$, \\ Mirela Jobim Azevedo ${ }^{1}$ and On Behalf of the Brazilian Type 1 Diabetes Study Group (BrazDiab1SG)
}

\begin{abstract}
Background: Brazilian records on glycemic control in patients with type 1 diabetes show treatment efficacy. Poor patient adherence to therapeutic proposals influences these results and can be associated with social, psychological, and economic aspects, besides others factors. The aim of this study was to evaluate the efficacy of psychological, telecare, and educational interventions to improve treatment compliance among patients with type 1 diabetes. Compliance was assessed indirectly using reduction of glycated hemoglobin (HbA1c) as the principal outcome measure.

Methods: Systematic review and meta-analyses of randomized controlled clinical trials (RCTs) were performed using Medline, Embase, Cochrane and Scopus databases up to April 2015. The following medical subject headings were used: Diabetes Mellitus, Type 1, Patient Compliance or Adherence, Hemoglobin A, glycated, and Randomized Controlled Trial. The principal outcome was change in $\mathrm{HbA1c}$ between baseline and follow-up. Where appropriate, trials were combined in meta-analysis using fixed effects models.

Results: From 191 articles initially identified, 57 were full text reviewed, and 19 articles met the inclusion criteria providing data from 1782 patients (49.4\% males, age 18 years). The RCTs (2 to 24 months in duration) were divided into four groups according to type of intervention: psychology (seven studies; 818 patients), telecare (six studies; 494 patients); education (five studies; 349 patients), and psychoeducation (one study; 153 patients). All studies reported some type of adherence measurement of the interventions. Decrease in HbA1c was observed after psychology (MD $-0.310 ; 95 \% \mathrm{Cl},-0.599$ to $-0.0210, P=0.035$ ) but not after telecare (MD $-0.124 \% ; 95 \% \mathrm{Cl},-0.268,0.020 ; P=0.090)$ or educational $(\mathrm{MD}-0.001 ; 95 \% \mathrm{Cl},-0.202,0.200$; $P=0.990)$ interventions.

(Continued on next page)
\end{abstract}

\footnotetext{
* Correspondence: vercoza@yahoo.com

${ }^{1}$ Endocrinology Division, Hospital de Clínicas de Porto Alegre, Universidade Federal do Rio Grande do Sul, Rua Ramiro Barcelos 2350, Prédio 12, $4^{\circ}$ andar, 90035-003 Porto Alegre, RS, Brazil

Full list of author information is available at the end of the article
} 
(Continued from previous page)

Conclusion: Psychological approaches to improve adherence to diabetes care treatment modestly reduced $\mathrm{HbA} 1 \mathrm{c}$ in patients with type 1 diabetes; telecare and education interventions did not change glycemic control. However, the limited number of studies included as well as their methodological quality should be taken into account.

Keywords: Adherence, Non-pharmacological interventions, Type 1 diabetes, Systematic review, Meta-analyses

\section{Background}

A seminal study published in recent decades clearly demonstrated that intensive glycemic treatment promoting lower glycated hemoglobin (HbA1c) values, as compared to standard care, can prevent or postpone chronic diabetic complications [1]. Furthermore, follow-up of these patients after the end-of-studies demonstrated that past strict glycemic control was associated with a low prevalence of complications years later. Patients intensively treated early in the course of type 1 diabetes less frequently developed impaired glomerular filtration rate [2], increased urinary albumin excretion $[2,3]$, and also had a lower risk of cardiovascular disease [4] than those treated with conventional diabetes therapy. Reduction in the risk of cardiovascular, renal, and ocular disease by strict glycemic control was recently reinforced in a systematic review in these patients [5].

HbA1c measurement has been widely used to evaluate glycemic control in patients with diabetes. It reflects the average glycemia over several months [6] and should be measured every 3 months. Whenever possible HbAlc targets should be maintained as close as possible to the nondiabetic levels $(<6.5 \%)$ but goals must be individualized by age and by the presence of chronic diabetic complications [7]. Diabetes management requires adherence to a complex daily therapeutic regimen in order to reduce HbA1c levels. Patients have to be able to adhere to many procedures such as self-blood glucose monitoring, diet plan, insulin administration and dose titration, and exercise [6].

Although epidemiological data on patients with type 1 diabetes in Brazil are still scarce, incidence seems to be increasing (incidence rate of 18.49/100,000) [8]. Indeed, the direct medical costs of type 1 diabetes in Brazil are about US\$1319.15 per patient for our national health service, not including the expenditure on chronic diabetic complications [9]. This aspect is relevant since the majority of our patients are at high risk of developing chronic diabetic complications. A survey conducted in 573 patients with type 1 diabetes in the south of Brazil demonstrated a high prevalence of diabetic retinopathy (43.3\%) and diabetic kidney disease (34.5\%) [10].

Despite advances in therapeutics, poor glycemic control is still a reality in many type 1 diabetic patients $[11,12]$. Accordingly, up to $78 \%$ of Brazilian patients with type 1 diabetes do not attain glycemic targets. Table 1 shows mean $\mathrm{HbA} 1 \mathrm{c}$ and the percentage of patients with type 1 diabetes who attain glycemic targets in different Brazilians centers.

Poor compliance with diabetes treatment is probably an important determinant of poor glycemic control observed in patients with type 1 diabetes. As adherence to treatment increases, HbA1c decreases as demonstrated by a meta-analysis of 21 cross-sectional studies including 2492 youth with type 1 diabetes [13]. Multicomponent adherence or self-management promoting interventions seems to be more potent than single ones, although with a borderline beneficial effect on HbA1c [14]. Many factors have been associated with adherence to diabetes treatment and glycemic control such as economic status [15], access to diabetes care [16] and devices to selfmonitor blood glucose [17], family support [18], social and peer pressures [19], interactions with their healthcare providers [16], presence of depression [18], and

Table 1 Mean glycated hemoglobin ( $\mathrm{HbA1c}$ ) and percentage of patients with type 1 diabetes who are on glycemic target in Brazilian centers

\begin{tabular}{lllll}
\hline Author & Number & Region of Brazil & $\begin{array}{l}\text { HbA1c (\%) } \\
\text { (mean } \pm \text { SD) }\end{array}$ & $\begin{array}{c}\text { Percentage of } \\
\text { patients on } \\
\text { glycemic } \\
\text { target* }\end{array}$ \\
\hline Rodrigues et al. $2010[10]^{\text {d }}$ & 573 & South & $9.0 \pm 3.9$ & $22.0 \%$ \\
Mendes et al. $2010[49]^{\text {b }}$ & 979 & South, Southeast, Northeast, Middle-west & - & $7.0 \%$ \\
Gomes et al. $2012[50]^{c}$ & 3591 & South, Southeast, North/Northeast, Middle-west & $9.1 \pm 2.3$ to $9.4 \pm 2.6$ & 12.2 to $21.4 \%$ \\
Gomes et al. $2012[51]^{d}$ & 1774 & South, Southeast, North/Northeast, Middle-west & $9.1 \pm 2.2$ & $11.6 \%$ \\
Viana et al. $2013[52]^{\mathrm{e}}$ & 1026 & South, Southeast, North/Northeast, Middle-west & $9.3 \pm 2.3$ & $13.0 \%$ \\
\hline
\end{tabular}

${ }^{*}$ Glycemic targets: ${ }^{\text {a, b}, ~ e ~} \mathrm{HbA} 1 \mathrm{c}<7.0 \%$; ${ }^{\mathrm{c}}$ d $\mathrm{HbA} 1 \mathrm{c}<7 \%$ - adults, $\mathrm{HbA} 1 \mathrm{c}<7.5 \%-13$ to 19 years, $\mathrm{HbA} 1 \mathrm{c}<8 \%-6$ to 12 years, $\mathrm{HbA} 1 \mathrm{c}>7.5 \%$ and $\mathrm{HbA} 1 \mathrm{c}<8.5 \%$ $-<6$ years 
transition to adolescence [18-20]. In this sense, nonpharmacological strategies for improving adherence to diabetes care, resulting in improved glycemic control, have been studied: psychological [21-29], telecare or Internet-based [30-35], educational [26, 36-38], and psychoeducational [39] interventions. Although other meta-analyses [30, 40], have already examined the effect of non-pharmacological interventions on compliance with diabetes treatment, the efficacy of such strategies is still uncertain.

Considering the poor glycemic control, the high prevalence of chronic diabetic complications, and the increasing worldwide prevalence of type 1 diabetes among children and adolescents $[41,42]$ it is crucial to identify factors that improve adherence to diabetes treatment. The aim of this study was to evaluate the efficacy of psychological, telecare, and educational interventions to improve treatment compliance among patients with type 1 diabetes. Compliance was assessed indirectly using reduction of $\mathrm{HbAlc}$ as the principal outcome measure.

\section{Methods}

This systematic review was carried out using a protocol constructed according to the Cochrane Handbook recommendations [43] and reported in accordance with Preferred Reporting Items for Systematic Reviews and Meta-Analyses (PRISMA) statement [44] (Additional file 1).

\section{Data sources and searches}

We searched databases from Medline, Embase, Cochrane, and Scopus to identify randomized controlled clinical trials (RCTs) that reported non-pharmacological interventions to improve adherence to diabetes treatment in patients with type 1 diabetes up to April 2015. The initial search comprised the following medical subject headings: "Diabetes Mellitus, Type 1" [Mesh], "Patient Compliance" [Mesh], or Adherence, "Hemoglobin A, Glycated" [Mesh], and related entry terms associated with a high sensitivity strategy for the search of RCTs available at http://www.sign.ac.uk/methodology/filters.html\#random (see Appendix section). All potentially eligible studies were considered for review, limited to the English, Spanish, or Portuguese language. A manual search was also performed in the reference lists of included articles.

\section{Study selection}

We included RCTs that reported changes in the HbA1c as differences between final and baseline interventions in RCTs. We excluded studies if they were not randomized, were crossover trials, included patients with type 1 and type 2 diabetes being analyzed together, included pregnant patients, or had no information about HbA1c.

\section{Data extraction and quality assessment}

All citations retrieved from electronic databases were imported to the EndNote Program. Two reviewers (MJA, LVV) independently analyzed the titles and abstracts of every paper retrieved from the literature search to identify potentially eligible studies. All studies that did not meet the inclusion criteria were excluded. The full text of the remaining papers was obtained for further examination. The same two reviewers using a standardized data extraction form independently extracted data of the included studies. Extracted data included first author's name, year of publication, number of participants, details of the study design (i.e., randomization method), trial duration, and patient characteristics (age, gender, ethnicity, diabetes duration). Studies were divided into four categories according to the type of intervention: psychology, telecare, education, and psychoeducation. Briefly, telecare intervention was defined as teleconsultation, tele-expertise, or telemonitoring [45]. Behavioral, multisystemic, and motivational approaches were considered a psychological intervention and any structured educational program as an educational intervention. Psychoeducation intervention was defined when psychological and educational tools were implemented at the same intervention.

Methodological quality assessment of included RCTs was independently assessed by the same two reviewers (MJA, LVV). We used the Cochrane Collaboration tool for assessing risk of bias of every included study. According to the Cochrane Collaboration, biases were classified into six domains: selection, performance, detection, attrition, reporting, and other [43, 46]. The risk of bias for each domain was classified as high, low, or unclear.

\section{Data synthesis and analysis}

Descriptive data from the systematic review were presented as mean and/or range, when available. We analyzed $\mathrm{HbA1c}(\%)$ as a continuous variable and reported HbA1c changes as absolute differences between arithmetic means at baseline and end-of-study and mean differences (MD) were used in the analyses (fixed models).

The heterogeneity between the studies was evaluated by Cochran's chi-squared test ( $Q$ test) and a $P$ value for trend $\leq 0.10$ was considered statistically significant. The $I^{2}$ test was also performed to evaluate the magnitude of heterogeneity [47] and statistical heterogeneity was considered in the presence of $I^{2}$ values $>75 \%$. Subgroup analyses were performed including only RCTs conducted with children and teenagers.

All statistical analyses will be performed using Stata 11.0 software (StataCorp, College Station, TX, USA). Significance was set at $P<0.05$ and $95 \%$ confidence intervals are quoted throughout. 


\section{Results}

Literature search

We identified 191 studies in database searches. Of these, 67 studies were excluded due to duplication. Another 67 articles were excluded based on title or abstract: 24 studies were not performed in patients with type 1 diabetes; 31 studies had no information about treatment compliance; seven studies did not report HbA1c; and five studies had a non-randomized design. Then we evaluated the full texts of 57 articles. Two additional papers identified in the references of the revised articles were also fully evaluated. Hence, from a total of 57 studies, 40 were excluded and 19 trials, which fulfilled all selection criteria, were included in the current systematic review (Fig. 1).

\section{Study characteristics}

This systematic review included a total of 1782 patients with type 1 diabetes aged 18 years (12 to 46), $49.4 \%$ males, $71.6 \%$ of white ethnicity, and with a mean duration of diabetes of 9.3 years (3.7 to 23). Baseline mean HbA1c in intervention groups ranged from $8.2 \%$ to $11.4 \%$ and from $8.2 \%$ to $11.3 \%$ in the control groups. Trial duration varied from 2 to 24 months.

RCT characteristics according to each intervention category are described in Table 2. Table 3 depicts risk of bias in each individual RCT evaluating interventions to improve compliance with lower $\mathrm{HbA1c}$ in patients with type 1 diabetes. Most of the quality domains of studies included in these meta-analyses revealed a low or uncertain bias risk.
The data available from the reviewed RCTs allowed us to perform meta-analyses of psychological, educational, and telecare interventions. Only one trial evaluated combined psychological and educational interventions (psychoeducation category). Therefore, this trial was included only in the systematic review.

\section{Psychological interventions}

Systematic review of psychological interventions included six RCTs [21-29] and 783 patients aged 16.4 years ( 8 to $47)$, most of them, but one [26] conducted in children and adolescents. Patients were mostly white (75 \%) and about half of them were male with a mean diabetes duration of 7 years (4 to 24) years. Baseline HbA1c in intervention was $9.2 \%(8.7$ to $11.4 \%)$ and $9.1 \%(8.2$ to $11.3 \%)$ in the control group. Duration of intervention was 10.2 months (11 weeks to 24 months). The psychological approaches used in RCTs are described in Table 1.

Nine studies were initially considered for inclusion in the psychological interventions meta-analysis [21-24, 26, 28]. However, the four studies conducted by Ellis et al. [21-24] presented complementary data and the same patients were evaluated. Then, we included data of only one study to avoid including the same individuals inappropriately twice in the pooled estimate. Therefore, four studies which presented baseline and end-of-study data were included in this meta-analysis.

The interventions promoted a significant reduction in HbA1c (MD -0.310\%; $95 \%$ CI, $-0.599,-0.021 ; P=0.035)$.

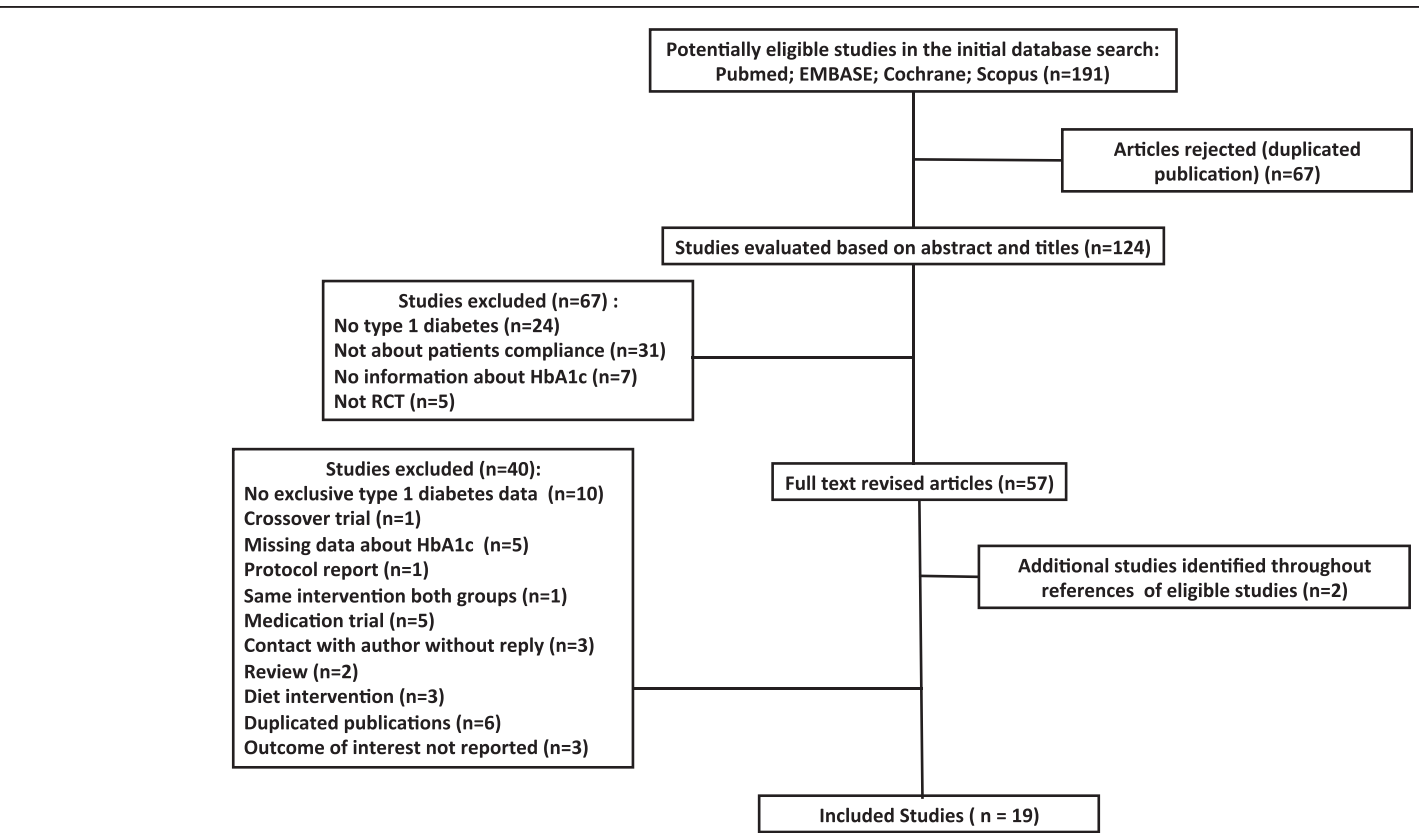

Fig. 1 Flow diagram of literature search to identify randomized clinical trials evaluating interventions to improve compliance with lower glycated hemoglobin $(\mathrm{HbA1c})$ values in patients with type 1 diabetes 
Table 2 Characteristics of included randomized clinical trials evaluating interventions to improve compliance with lower glycated hemoglobin (HbA1c) in patients with type 1 diabetes according to intervention categories

\begin{tabular}{|c|c|c|c|}
\hline Study & Sample & Intervention and Control groups & HbA1c changes/comments \\
\hline \multicolumn{4}{|l|}{$\begin{array}{l}\text { Psychological } \\
\text { category }\end{array}$} \\
\hline $\begin{array}{l}\text { Ellis, } 2005,2007 \text { [21- } \\
\text { 24] (4 published } \\
\text { complementary } \\
\text { reports) }\end{array}$ & $\begin{array}{l}n=127 \text { Age }=13.3 \text { years Diabetes } \\
\text { duration }=5.3 \text { years Male }=62(48 \%) \\
\text { White }=33(26 \%)\end{array}$ & $\begin{array}{l}\text { Intervention Multisystemic therapy: intensive and home- and } \\
\text { community-based, originally designed for youths with antisocial } \\
\text { behavior. Duration of intervention: } 5.7 \text { months Control Standard } \\
\text { medical care: quarterly visit of multidisciplinary team }\end{array}$ & $\begin{array}{l}\text { Intervention Baseline }=11.4 \pm 2.2 \% \text { End-of-study }=10.8 \pm \\
2.6 \% \text { Control Baseline }=11.3 \pm 2.3 \% \text { End-of-study }=11.3 \\
\pm 2.3 \% \text { Significant reduction of HbA1c only in the interven- } \\
\text { tion group Compliance evaluation of the psychological inter- } \\
\text { vention: semi structured interview }\end{array}$ \\
\hline
\end{tabular}

Nansel, $2007[25] \quad n=81$ Age $=13.6$ years Diabetes duration $=7.6$ years Male $=36(44 \%)$ White $=69(85 \%)$

Weinger, 2011 [26] $\quad n=110^{\mathrm{a}}$ Age $=46.6$ years Diabetes duration $=23.7$ years Male $=48(48 \%)$ White $=105(96 \%)$

Nansel, 2012 [27] $\quad n=390$ Age $=12.5$ years Diabetes duration $=4.8$ years Male $=191(49 \%)$ White $=273(70 \%)$

Mulvaney, 2010 [28] $n=72$ Age $=15.1$ years Diabetes duration: 6.3 years Male $=40(56 \%)$ White $=66(92 \%)$

Franklin, $2006[29] \quad n=61$ Age $=13.5$ years Diabetes duration $=4.1$ years Male $=34(56 \%)$ White $=59(97 \%)$ Results referred only to patients on conventional insulin arm

Telecare category

Montori, 2004 [30]

$n=31$

Age $=43$ years Diabetes duration $=17$ years Male $=10(32 \%)$ White $=$ no information

Lawson, $2005[31] \quad n=46$ Age $=15.2$ years Diabetes duration $=6.5$ years Male $=26(56 \%)$ White $=$ no information
Intervention "Diabetes Personal Trainer": approach guided by principles of motivational interviewing, applied behavior analysis, and problem solving. Duration of intervention: 2 months Control Education plus standard diabetes care

Intervention Structured behavioral intervention: five 2-hour sessions. Duration of intervention: 6 weeks Control Individual appointments with diabetes nurse and dietitian educators

vention: semi structured interview

No significant reduction in $\mathrm{HbA1c}$ in intervention and control groups, but absolute values were not described Compliance evaluation of the psychological intervention: modified version of Diabetes -Management Profile

Intervention Baseline $=9.0 \pm 1.9 \%$ End-of-study $=8.7 \pm 1.2$ $\%$ Control Baseline $=8.7 \pm 0.6 \%$ End-of-study $=8.5 \pm 1.1$ $\%$ Changes of $\mathrm{HbA} 1 \mathrm{c}$ were described but statistical analysis was not reportedCompliance evaluation of the psychological intervention: frequency of diabetes self-care, 3-day pedometer readings, 24-hour diet recalls, average number of glucose checks.

Intervention Clinic-integrated behavioral: designed to improve family Significant reduction of HbA1c occurred only in the diabetes management (WE-CAN manage diabetes). Duration of intervention: 24 months Control Standard medical care

intervention group, but absolute values were not described Compliance evaluation of the psychological intervention: semi structured interview

Intervention Learning, social-cognitive and self-determination management by website support. Duration of intervention: 11 weeks. Control Usual care

Intervention Baseline $=9.1 \pm 1.9 \%$ End-of -study $=9.1 \pm$ $1.8 \%$ Control Baseline $=8.2 \pm 1.2 \%$ End-of-study $=8.5 \pm$ $1.3 \%$ No significant reduction in $\mathrm{HbA1c}$ in intervention and control groups Compliance evaluation of the psychological intervention: The Diabetes Rating Scale

Intervention "Sweet talk": motivational support network to deliver behavioral intervention through mobile. Duration of intervention: unclear Control Usual care

Intervention Baseline $=9.8 \%$ End-of-study $=10.1 \pm 1.7 \%$ Control Baseline $=10.1 \%$ End-of-study $=10.3 \pm 1.7 \%$ No significant reduction in $\mathrm{HbA} 1 \mathrm{C}$ in intervention and control groups Compliance evaluation of the psychological intervention: self-report adherence

Intervention Monitoring blood glucose four times/day and transmitting recorded data twice a week with feedback from a nurse supervised by an endocrinologist 24 hours after the transmission. Duration of intervention: 6 months Control Same monitoring requested but without feedback

Intervention Weekly standardized telephone contact with a diabetic nurse specialist to discuss blood sugar over the last week and performing insulin adjustments using standard rules and algorithms.

Intervention Baseline $=9.3 \pm 1.3 \%$ End-of-study $=7.8 \pm 1.3$ $\%$ Control Baseline $=8.8 \pm 1.2 \%$ End-of-study $=8.2 \pm 1.2$ $\%$ Significant reduction of $\mathrm{HbA} 1 \mathrm{c}$ only in the intervention group Compliance evaluation of the telecare intervention: SMBG and insulin use

Intervention Baseline $=10 \pm 1.3 \%$ End-of-study $=9.4 \pm 1.4$ $\%$ Control Baseline $=9.7 \pm 0.6 \%$ End-of-study $=9.2 \pm 1.4$ $\%$ No significant reduction of $\mathrm{HbA} 1 \mathrm{c}$ in intervention and control groups Compliance evaluation of the telecare 
Table 2 Characteristics of included randomized clinical trials evaluating interventions to improve compliance with lower glycated hemoglobin (HbA1c) in patients with type 1 diabetes according to intervention categories (Continued)

Farmer, $2005[32] \quad \begin{aligned} & n=93 \text { Age }=23.8 \text { years Diabetes } \\ & \text { duration }=12.1 \text { years Male }=55\end{aligned}$ duration $=12.1$ years Male $=55$
$(59 \%)$ White $=$ no information

Landau, 2011 [33] $\quad n=70$ Age $=15$ years Diabetes duration $=5.7$ years Male $=32(46 \%)$ White $=$ no information

Gay, $2006[34] \quad n=100$ Age $=13.3$ years Diabetes duration $=6.2$ years Male $=32(61 \%)$ White $=$ no information

Esmatjes, 2014 [35] $\quad n=154$ Age $=31.7$ years Diabetes duration $=17.7$ years Male $=69(44.9 \%)$ White $=$ no information

Educational category Cook, 2002 [36]

$n=53$ Age $=14.6$ years Diabetes duration $=$ no information Male $=26(49 \%)$ White $=45(85 \%)$

Howe, 2005 [37] $n=49$ Age $=12.8$ years Diabetes duration $=$ no information Male $=28(57 \%)$ White $=27(55 \%)$

$n=54$ Age $=12.1$ years Diabetes duration: no information Male $=29(54 \%)$ White $=28(52 \%)$
Duration of intervention: 6 months Control Standard care with quarterly visit with a nurse and an endocrinologist

Intervention Clinical advice and structured specialized nurse counseling in response to real-time blood glucose test results. Duration of intervention: 9 months Control Data transmission without feedback

Intervention Weekly upload of the self-monitoring blood glucose and feedback from study coordinator. Parents were contacted if any chang in the treatment was necessary. Duration of intervention: 6 months Control Data upload without study coordinator feedback

Intervention Twice a month children went to a selected pharmacy to download data stored in their glucometer. Data was transmitted to a pediatric diabetologist and within 5 days feedback was provided. Duration of intervention: 6 months Control Usual follow-

Intervention Five telematic visits, and management of the Medica Guard Diabetes (MGD) system (Pulso Ediciones, Barcelona, Spain) with data reports once a month and responses of diabetes team in the following 3 days with recommendations on treatment adjustments. Duration of intervention: 6 months Control All visits were in hospital and data were obtained on site during the visits

Intervention Small group education to teach adolescents to became more responsible with day-to-day diabetes care (Choices Program). Duration of intervention: 6 weeks Control Usual care Intervention Single educational intervention to provide families with
basic diabetes management skills. Duration of intervention: one session Control Standard care with quarterly visit with a nurse practitioner and an endocrinologist

Intervention Single educational intervention to provide families with basic diabetes management skills plus weekly phone calls for 3 months and then bimonthly. Study coordinator followed a standard protocol on the phone talking about problem-solving skills related to diabetes care. Duration of intervention: 6 months Control Standard care with quarterly visit with nurse practitioner and an endocrinologist intervention: general adherence with diabetes management (blood glucose testing, insulin schedule, food plan, glucose goals, exercise)

Intervention Baseline $=9.2 \pm 1.1 \%$ End-of-study $=8.6 \pm 1.4$ $\%$ Control Baseline $=9.3 \pm 1.5 \%$ End-of-study $=8.9 \pm 1.4 \%$ Significant reduction of HbA1c in intervention and control groups, without difference between them Compliance evaluation of the telecare intervention: SMBG

Intervention Baseline $=8.5 \pm 1.4 \%$ End-of-study $=8.5 \pm 1.4$ Control Baseline $=8.2 \pm 1.1 \%$ End-of-study $=8.4 \pm 1.1 \%$ No significant reduction of $\mathrm{HbA} 1 \mathrm{c}$ in intervention and control groups Compliance evaluation of the telecare intervention: SMBG

ntervention Baseline $=9.2 \pm 1.1 \%$ End-of-study $=9.1 \pm 1.5$ $\%$ Control Baseline $=9.2 \pm 1 \%$ End-of-study $=9.3 \pm 1.2 \%$ No significant reduction of $\mathrm{HbAlc}$ in intervention and control groups. There were problems with software installation tion of the telecare in and insulin adjustments

Intervention Baseline $=9.3 \pm 1.5 \%$ End-of-study $=8.7 \pm 1.5$ $\%$ Control Baseline $=92+0.9 \%$ End-of-study $=8.6 \pm 0.9$ $\%$ No significant reduction of $\mathrm{HbA1c}$ between intervention and control groups Compliance evaluation of the telecare intervention: self-care treatment adherence

Intervention Baseline $=8.9 \pm 1.3 \%$ End-of-study $=8.3 \pm 1.4$ $\%$ Control Baseline $=9.3 \pm 2.1 \%$ End-of-study $=9.0 \pm$ $1.9 \%$ No significant reduction of HbA1c in intervention and control groups at 6 months Compliance evaluation of the educational intervention: SMBG and Diabetes Problem Solving Questionnaire

Intervention Baseline $=10.1 \pm 1.2 \%$ End-of-study $=9.7 \pm$ $1.9 \%$ Control Baseline $=10.2 \pm 1.4 \%$ End-of-study $=9.9 \pm$ $1.6 \%$ No significant reduction of $\mathrm{HbA} 1 \mathrm{C}$ in intervention and control groups Compliance evaluation of the educational intervention: Adherence Clinician Checklist

Intervention Baseline $=10 \pm 1.4 \%$ End-of-study $=9.5 \pm$ $1.7 \%$ Control Baseline $=10.2 \pm 1.4 \%$ End-of-study $=$ $9.9 \pm 1.6 \%$ No significant reduction of HbA1c in intervention and control groups Adherence / Compliance evaluation: Adherence Clinician Checklist. 
Table 2 Characteristics of included randomized clinical trials evaluating interventions to improve compliance with lower glycated hemoglobin (HbA1c) in patients with type 1 diabetes according to intervention categories (Continued)

Weinger, $2011[26] \quad n=110^{\mathrm{b}}$ Age $=46.6$ years Diabetes duration $=23.7$ years Male $=48(48 \%)$ White $=105(96 \%)$

Nunn, $2006[38]$

$n=123$ Age $=11.6$ years Diabetes duration $=3.7$ years Male $=69(56 \%)$ White $=$ no information

Psychoeducation

category

Katz, 2014 [39] $n=153$ Diabetes duration $=12.8$ years Male $=67(44 \%)$ White $=$ no information
Intervention Five 2-hour sessions of manual-based group diabetes education Duration of intervention: 6 weeks Control Individual appointments with diabetes nurse and dietitian educators

Intervention Bimonthly phone calls from a diabetes educator covering the three main topics insulin use, carbohydrate intake and blood glucose values with a written educational program. Duration of intervention: 7 months Control Usual care

Intervention 1 Psychoeducation was performed as 30-minute

quarterly sessions with the patient parent or guardian and ment of diabetes, problem-solving exercises and role playing realistic expectations, glucose self-monitoring, avoidance of weight gain, and hypoglycemia. Duration of intervention: 2 years Intervention 2 Participants received monthly outreach by the care ambassador via phone or email, in addition to the quarterly diabetes care and ambassador care coordination. Duration of intervention: 2 years Intervention 3 Standard care including basic care coordination by the care ambassador (to assist in scheduling quarterly clinic visits)
Results of HbA1c were described together for patients with type 1 and type 2 diabetes Compliance evaluation of the educational intervention: frequency of diabetes self-care, 3day pedometer readings, 24-hour diet recalls, average number of glucose checks

Intervention Baseline $=8.2 \pm 1.1 \%$ End-of-study $=8.9 \pm 1.3$ $\%$ Control Baseline $=8.3 \pm 1.01 \%$ End-of-study $=8.8 \pm 1.1$ $\%$ No significant reduction of $\mathrm{HbA1c}$ in intervention and control groups at 6 months Compliance evaluation of the educational intervention: SBGM, limited screen time, exercise practice, rotation of injection sites, warrant bracelets worn

Intervention 1 Baseline $=8.3 \pm 1.4 \%$ End-of-study $=8.6 \pm$ $1.0 \%$ Intervention 2 Baseline $=8.5 \pm 1.4 \%$ End-of-study $=$ $8.8 \pm 1.0 \%$ Intervention 3 Baseline $=8.5 \pm 1.4 \%$ End-ofstudy $=8.6 \pm 1.0 \%$ No significant reduction of $\mathrm{HbAlc}$ in intervention and control groups

at 2 years Compliance evaluation of the educationa intervention: Diabetes Family Responsibility Questionnaire

a Results referred to two out of three study arms: behavior versus individual care; $\mathrm{HbA1c}$ results were from 73 patients

${ }^{\mathrm{b}}$ Results referred to two out of three study arms: educational versus individual care; $\mathrm{HbA} 1 \mathrm{c}$ results were from 73 patients 
Table 3 Meta-analysis: risk of bias in individual randomized clinical trials evaluating interventions to improve compliance to lower glycated hemoglobin (HbA1c) in patients with type 1 diabetes according to intervention category

\begin{tabular}{|c|c|c|c|c|c|c|}
\hline & Selection bias & & Performance bias & Detection bias & Attrition bias & Reporting bias \\
\hline & $\begin{array}{l}\text { Random sequence } \\
\text { generation }\end{array}$ & $\begin{array}{l}\text { Allocation } \\
\text { concealment }\end{array}$ & $\begin{array}{l}\text { Blinding of participant } \\
\text { and personnel }\end{array}$ & $\begin{array}{l}\text { Blinding of outcome } \\
\text { assessment }\end{array}$ & $\begin{array}{l}\text { Incomplete } \\
\text { outcome data }\end{array}$ & $\begin{array}{l}\text { Selective } \\
\text { reporting }\end{array}$ \\
\hline \multicolumn{7}{|l|}{ Psychology category } \\
\hline Ellis, $2005-2007^{b}$ & low & low & low & low & uncertain & low \\
\hline Nansel, 2007 & low & low & low & low & high & uncertain \\
\hline Weinger, $2011^{a}$ & low & low & low & low & uncertain & low \\
\hline Nansel, 2011 & low & low & high & uncertain & high & low \\
\hline Mulvaney, 2010 & low & low & uncertain & uncertain & uncertain & uncertain \\
\hline Franklin, 2006 & low & low & low & uncertain & uncertain & low \\
\hline \multicolumn{7}{|l|}{ Telecare category } \\
\hline Montori, 2004 & low & low & low & uncertain & uncertain & low \\
\hline Lawson, 2005 & low & low & low & low & uncertain & low \\
\hline Farmer, 2005 & low & low & low & low & uncertain & low \\
\hline Landau, 2011 & low & low & low & low & uncertain & low \\
\hline Gay, 2006 & low & low & low & low & uncertain & low \\
\hline Esmatjes, 2014 & low & low & uncertain & uncertain & uncertain & low \\
\hline \multicolumn{7}{|l|}{ Education category } \\
\hline Cook, 2002 & uncertain & uncertain & low & uncertain & uncertain & low \\
\hline Howe, 2005 & uncertain & uncertain & uncertain & low & uncertain & low \\
\hline Weinger, $2011^{\mathrm{b}}$ & low & low & low & low & uncertain & low \\
\hline Nunn, 2006 & low & low & low & low & uncertain & low \\
\hline
\end{tabular}

${ }^{a}$ The same study had three arms evaluated as: psychology versus individual care and education versus individual care interventions

${ }^{b}$ Four published complementary reports

No heterogeneity was found in this analysis $\left(I^{2} 0 \%\right.$; $P=0.615)$.

\section{Telecare interventions}

Systematic review of telecare interventions evaluated six RCTs [30-35], including 494 patients with mean age 25.8 (13 to 43 years). No information about ethnicity was provided and about half of patients were males. Diabetes duration was 11.43 years $(5.7-17.2)$. The length of most studies was 6 months and only one lasted for 9 months. The description of telecare interventions used in RCTs is shown in Table 1.

All six RCTs were included in the meta-analysis of telecare intervention. The HbA1c of patients submitted to telecare interventions was not reduced during trials (MD $-0.124 \%$; $95 \% \mathrm{CI},-0.268,0.020 ; P=$ 0.090) (Fig. 2). No heterogeneity was found in this analysis $\left(I^{2} 35.8 \% ; P=0.168\right)$.

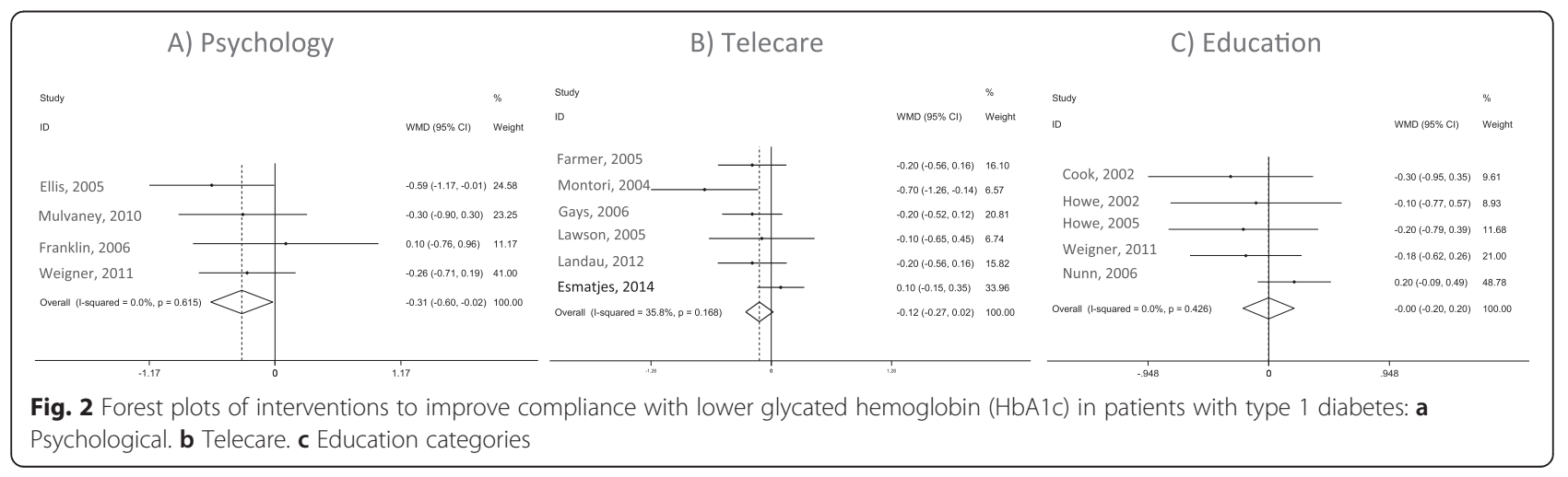




\section{Educational interventions}

Systematic review of educational interventions included four RCTs [26, 36-38] and 352 patients 19.6 years old (12 to 46). Trials were conducted mainly in children and adolescents. Patients were mostly white (65\%) and about half of them were male. Mean diabetes duration was described in only two studies. The duration of intervention varied from a single session to 12 months. The educational interventions used in RCTs are described in Table 1.

In the meta-analysis of included RCTs, five interventions were evaluated in four trials. No change in HbA1c was observed with educational approaches (MD -0.001\%; $95 \% \mathrm{CI},-0.202,0.200 ; P=0.990$ ) (Fig. 2). No heterogeneity was found in this analysis $\left(I^{2} 0 \% ; P=0.426\right)$.

\section{Psychoeducation intervention}

One trial combined psychological and educational intervention [39] including 153 patients with type 1 diabetes (44 \% males, age 12.8 years) and evaluated three intervention arms. The psychoeducation arm consisted in 30minute quarterly sessions. Psychoeducational material was related to family management of diabetes, avoiding perfectionism and setting realistic goals (psychological intervention), and glucose self-monitoring, weight gain, and hypoglycemia (educational intervention). Psychoeducational intervention was compared to usual care or usual care plus monthly phone calls or email reinforcements. Care from a non-medical ambassador occurred in all study arms. There was no difference in HbA1c among groups at 2 years.

\section{Subgroup analyses}

Twelve of the 18 meta-analyzed trials were conducted only in children and adolescents. We re-ran analyses maintaining only these 12 RCTs [21-24, 28, 29, 33-37]. Results of these meta-analyses are described in Table 4. No intervention (psychology, telecare, education) was able to reduce $\mathrm{HbA1c}$ in this age specific population. No heterogeneity was found in any meta-analysis.

\section{Discussion}

This was a systematic review of interventions aiming to reduce $\mathrm{HbA} 1 \mathrm{c}$ in patients with type 1 diabetes by improving compliance with therapy. The review considered 1782 individuals from 19 RCTs. We were able to perform three meta-analyses according to the type of interventions: psychology, telecare, and education. Psychological interventions were associated with $\mathrm{HbA1c}$ reduction (MD -0.310; $95 \%$ $\mathrm{CI},-0.599$ to $-0.0210, P=0.035)$ but not meta-analyses of telecare (MD -0.124 \%; $95 \% \mathrm{CI},-0.268,0.020 ; P=0.090$ ) or educational (MD $-0.001 ; 95 \% \mathrm{CI},-0.202,0.200 ; P=$ $0.990)$ interventions.

Tight glycemic control is difficult to obtain in type 1 diabetic patients and any intervention that reduces $\mathrm{HbAlc}$ is extremely helpful in controlling their diabetes. We identified two other systematic reviews on adherence in the medical literature $[13,14]$. One of them analyzed crosssectional studies [13]. The other study evaluated adherence or self-management promoting strategies. However, the authors performed a meta-analysis including all different categories of intervention together and showed no improvement in glycemic control [14]. We believe that stratifying intervention categories (such as psychology, education, telecare), as we did in the current study, is a more adequate statistical approach. In addition, it is important to emphasize that our literature search method was quite unique: we performed an open search for RCTs that improved patient compliance instead of searching for specific interventions. This strategy could explain the differences between our results and the previous reviews. We also excluded crossover trials because it is hard to perform an adequate washout when dealing with subjective interventions.

A systemic review of psychological and educational interventions in adolescents with type 1 diabetes [40] seemed to reduce $\mathrm{HbA1c}$ for both interventions but the confidence interval for HbA1c changes was quite large. Furthermore, this review was not projected to evaluate whether the studied interventions were associated with patients' compliance with the diabetes treatment. Regarding telecare intervention, a meta-analysis conducted in patients with type 1 diabetes did not reduce HbA1c [30], similar to our results. However, that study was not aimed to reduced HbA1c [30], and once again this study was not designed to evaluate compliance.

Most children and teenagers with type 1 diabetes do not meet traditional glycemic control targets [11] and

Table 4 Subgroup meta-analyses: changes in glycated hemoglobin ( $\mathrm{HbA} 1 \mathrm{c})(\%)$ in randomized clinical trials evaluating interventions to improve compliance with lower $\mathrm{HbA1c}$ in children and teenagers with type 1 diabetes

\begin{tabular}{|c|c|c|c|c|c|}
\hline \multirow[t]{2}{*}{ Type of intervention } & \multirow{2}{*}{$\begin{array}{l}\text { Number } \\
\text { of } \\
\text { studies }\end{array}$} & \multirow{2}{*}{$\begin{array}{l}\text { Number } \\
\text { of } \\
\text { patients }\end{array}$} & $\mathrm{MD}$ & \multirow[t]{2}{*}{$95 \% \mathrm{Cl}$} & \multirow[t]{2}{*}{$P$} \\
\hline & & & $\mathrm{HbA1c}$ & & \\
\hline Psychological [21-24, 28, 29] & 3 & 239 & $-0.34 \%$ & -0.72 to $0.035 \%$ & 0.083 \\
\hline Telecare [32-35] & 3 & 554 & $-0.18 \%$ & -0.40 to $0.03 \%$ & 0.098 \\
\hline Educational [36-38] & 4 & 631 & 0.046 & -0.80 to 0.272 & 0.689 \\
\hline
\end{tabular}


recently the American Diabetes Association reduced HbA1c goals for youth [12]. Interestingly, in our data search we found that most studies were performed in children and adolescents. Therefore, we decided to perform a subgroup analysis including only these patients. Indeed, the management of children and teenagers with diabetes usually has peculiarities, including nonpharmacological interventions (e.g., family involvement) [18]. Unfortunately, we were not able to confirm benefits of any studied intervention in this specific population similar to those described by other authors [40]. Inclusion of a greater number of studies in pediatric patients could have shown improvement in glycemic control since there is still a clear trend to lower HbA1c by psychological intervention according to our subgroup analysis.

A possible limitation of our systematic review could be the small number of studies in each intervention category. Since we performed complete-case analyses [48], the missing data in some of reviewed trials precluded their inclusion in our meta-analyses. In theory the choice to use only studies that report baseline and final values could lead to the possibility of selective reporting [43]. Indeed, analyses based on changes from baseline will be more efficient and powerful than comparisons of final values [43], especially when analyzing HbA1c values. The quality of included studies could represent a weakness in our meta-analyses. Nevertheless, only the study of Nansel et al. [27] included a psychological intervention and there were two high domain biases: blinding bias, which was not truly applicable to this type of intervention, and incomplete data. All other studies included revealed a low or uncertain bias risk. Contact with nonresponding authors remains a problem in performing meta-analyses since we could not recover any missing data after personal contact. It would be interesting to compare all included trials through a network metaanalysis. However, different strategies without a common comparator prevented us from performing this analysis.

\section{Conclusion}

We performed this systematic review because there was no clear information available regarding which kind of intervention should be used to improve compliance with general diabetes treatment aimed at lowering $\mathrm{HbA} 1 \mathrm{c}$ (improvement of glycemic control). Unfortunately, so far we could only demonstrate psychological intervention as the sole evidence-based recommendation; the number of included studies was relatively low but their quality allowed us to conclude that this tool can be useful in the management of diabetic patients. In conclusion, we demonstrated that in patients with type 1 diabetes psychological interventions to improve patients' compliance with diabetes treatment did improve glycemic control.

\section{Appendix}

\section{Research strategy}

Medline

((((“Randomized Controlled Trial”[Publication Type]) AND "Diabetes Mellitus, Type 1"[Mesh]) AND "Patient Compliance"[Mesh]) AND “Hemoglobin A, Glycated”[Mesh])

\section{Additional file}

Additional file 1: PRISMA 2009 Checklist. (DOC 63 kb)

\section{Abbreviations}

HbA1c: glycated hemoglobin; MD: mean differences; PRISMA: Preferred Reporting Items for Systematic Reviews and Meta-Analyses; RCT: randomized controlled clinical trial.

\section{Competing interests}

The authors declare that they have no competing interests.

\section{Authors' contributions}

LW and MJA were engaged in conception and design, data extraction, statistical analyses and interpretation of data and drafting of the manuscript. MBG was involved in conception, data interpretation, and manuscript revision. $L Z$ and EJP reviewed the manuscript and researched the data. LW is the guarantor of this work and, as such, had full access to all the data in the study and takes responsibility for the integrity of the data and the accuracy of the data analysis. All authors also read and approved the final manuscript.

\section{Acknowledgements}

Conselho Nacional de Desenvolvimento Científico e Tecnológico (CNPq), Coordenação de Aperfeiçoamento de Pessoal de Nível Superior (CAPES), and Fundo de Incentivo à Pesquisa (FIPE) of Hospital de Clínicas de Porto Alegre (HCPA).

\section{Author details}

${ }^{1}$ Endocrinology Division, Hospital de Clínicas de Porto Alegre, Universidade Federal do Rio Grande do Sul, Rua Ramiro Barcelos 2350, Prédio 12, $4^{\circ}$ andar, 90035-003 Porto Alegre, RS, Brazil. 'Unit of Diabetes, Universidade Estadual do Rio de Janeiro, Rio de Janeiro, Brazil. ${ }^{3}$ Internal Medicine Department, Diabetes Division, Hospital Universitário Clementino Fraga Filho, Universidade Federal do Rio de Janeiro, Rio de Janeiro, Brazil. ${ }^{4}$ Department of Clinical Medicine, Universidade Estadual de Campinas, Campinas, Brazil.

Received: 5 May 2015 Accepted: 30 January 2016

Published online: 17 February 2016

\section{References}

1. The Diabetes Control and Complications Trial Research Group. The effect of intensive treatment of diabetes on the development and progression of long-term complications in insulin-dependent diabetes mellitus. The Diabetes Control and Complications Trial Research Group. N Engl J Med. 1993. 329: $977-86$.

2. de Boer $\mathrm{H}$, Sun W, Cleary PA, Lachin JM, Molitch ME, Steffes MW, et al. Intensive diabetes therapy and glomerular filtration rate in type 1 diabetes. N Engl J Med. 2011;365:2366-76.

3. Epidemiology of Diabetes Interventions and Complications (EDIC). Sustained effect of intensive treatment of type 1 diabetes mellitus on development and progression of diabetic nephropathy: the Epidemiology of Diabetes Interventions and Complications (EDIC) study. JAMA. 2003. 290: 2159-67.

4. Nathan DM, Cleary PA, Backlund JY, Genuth SM, Lachin JM, Orchard TJ, et al. Intensive diabetes treatment and cardiovascular disease in patients with type 1 diabetes. N Engl J Med. 2005;353:2643-53.

5. Fullerton B, Jeitler K, Seitz M, Horvath K, Berghold A, Siebenhofer A. Intensive glucose control versus conventional glucose control for type 1 diabetes mellitus. Cochrane Database Syst Rev. 2014;2:CD009122. doi:10. 1002/14651858.CD009122.pub2.

6. American Diabetes Association. Standards of medical care in diabetes. Diabetes Care. 2015;38 Suppl 1:S1-S89. 
7. NGPS. Harmonizing hemoglobin A1c testing. Available at: http://www.ngsp. org/index.asp on 5 December 2015.

8. Negrato CA, Cobas RA, Gomes MB. Temporal changes in the diagnosis of type 1 diabetes by diabetic ketoacidosis in Brazil: a nationwide survey. Diabet Med. 2012;29:1142-7.

9. Cobas RA, Ferraz MB, Matheus AS, et al. The cost of type 1 diabetes: nationwide multicentre study in Brazil. Bull World Health Organ. 2013:91:434-40.

10. Rodrigues TC, Pecis M, Canani LH, Kramer CK, Schreiner L, Macedo B, et al. Caracterização de pacientes com diabetes mellitus tipo 1 do sul do Brasil: complicações crônicas e fatores associados. Rev Assoc Med Bras. 2010;56:67-73.

11. Chiang JL, Kirkman MS, Laffel LM, Peters AL. Type 1 diabetes through the life span: a position statement of the American Diabetes Association. Diabetes Care. 2014:37:2034-54

12. Wood JR, Miller KM, Maahs DM, Beck RW, DiMeglio LA, Libman IM, et al. Most youth with type 1 diabetes in the T1D Exchange Clinic Registry do not meet American Diabetes Association or International Society for Pediatric and Adolescent Diabetes clinical guidelines. Diabetes Care. 2013;36:2035-7.

13. Hood KK, Peterson CM, Rohan JM, Drotar D. Association between adherence and glycemic control in pediatric type 1 diabetes: a metaanalysis. Pediatrics. 2009;124:e1171-9.

14. Hood KK, Rohan JM, Peterson CM, Drotar D. Interventions with adherence-promoting components in pediatric type 1 diabetes: metaanalysis of their impact on glycemic control. Diabetes Care. 2010;33:1658-64.

15. Gomes MB, de Mattos Matheus AS, Calliari LE, Luescher JL, Manna TD, Savoldelli RD, et al. Economic status and clinical care in young type 1 diabetes patients: a nationwide multicenter study in Brazil. Acta Diabetol. 2013;50:743-52.

16. Schwartz DD, Cline VD, Hansen JA, Axelrad ME, Anderson BJ. Early risk factors for nonadherence in pediatric type 1 diabetes: a review of the recent literature. Curr Diabetes Rev. 2010;6:167-83.

17. Nyomba BLG, Berard L, Murphy LJ. Facilitating access to glucometer reagents increases blood glucose self-monitoring frequency and improves glycaemic control: a prospective study in insulin-treated diabetic patients. Diabet Med. 2004:21:129-35.

18. Malerbi FE, Negrato CA, Gomes MB. Assessment of psychosocial variables by parents of youth with type 1 diabetes mellitus. Diabetol Metab Syndr. 2012;4:48.

19. Borus JS, Laffel L. Adherence challenges in the management of type 1 diabetes in adolescents: prevention and intervention. Curr Opin Pediatr. 2010;22:405-11.

20. Rausch JR, Hood KK, Delamater A, Shroff Pendley J, Rohan JM, Reeves $G$, et al. Changes in treatment adherence and glycemic control during the transition to adolescence in type 1 diabetes. Diabetes Care. 2012;35:1219-24.

21. Ellis DA, Frey MA, Naar-King S, Templin T, Cunningham P, Cakan N. Use of multisystemic therapy to improve regimen adherence among adolescents with type 1 diabetes in chronic poor metabolic control: a randomized controlled trial. Diabetes Care. 2005;28:1604-10.

22. Ellis DA, Yopp J, Templin T, Naar-King S, Frey MA, Cunningham PB, et al. Family mediators and moderators of treatment outcomes among youths with poorly controlled type 1 diabetes: results from a randomized controlled trial. J Pediatr Psychol. 2007;32:194-205.

23. Ellis DA, Templin T, Naar-King S, Frey MA, Cunningham PB, Podolski CL, et al. Multisystemic therapy for adolescents with poorly controlled type diabetes: stability of treatment effects in a randomized controlled trial. J Consult Clin Psychol. 2007;75:168-74.

24. Cakan N, Ellis DA, Templin T, Frey M, Naar-King S. The effects of weight status on treatment outcomes in a randomized clinical trial of multisystemic therapy for adolescents with type 1 diabetes and chronically poor metabolic control. Pediatr Diabetes. 2007:8:206-13.

25. Nansel TR, lannotti RJ, Simons-Morton BG, Cox C, Plotnick LP, Clark LM, et al. Diabetes personal trainer outcomes: short-term and 1-year outcomes of a diabetes personal trainer intervention among youth with type 1 diabetes. Diabetes Care. 2007;30:2471-7.

26. Weinger K, Beverly EA, Lee Y, Sitnokov L, Ganda OP, Caballero AE. The effect of a structured behavioral intervention on poorly controlled diabetes: a randomized controlled trial. Arch Intern Med. 2011;171:1990-9.
27. Nansel TR, lannotti RJ, Liu A. Clinic-integrated behavioral intervention for families of youth with type 1 diabetes: randomized clinical trial. Pediatrics. 2012;129:e866-e73.

28. Mulvaney SA, Rothman RL, Wallston KA, Lybarger C, Dietrich MS. An Internet-based program to improve self-management in adolescents with type 1 diabetes. Diabetes Care. 2010;33:602-4.

29. Franklin VL, Waller A, Pagliari C, Greene SA. A randomized controlled trial of Sweet Talk, a text-messaging system to support young people with diabetes. Diabet Med. 2006;23:1332-8.

30. Montori VM, Helgemoe PK, Guyatt GH, Dean DS, Leung TW, Smith SA, et al. Telecare for patients with type 1 diabetes and inadequate glycemic control: a randomized controlled trial and meta-analysis. Diabetes Care. 2004;27:1088-94.

31. Lawson ML, Cohen N, Richardson C, Orrbine E, Pham B. A randomized trial of regular standardized telephone contact by a diabetes nurse educator in adolescents with poor diabetes control. Pediatr Diabetes. 2005;6:32-40.

32. Farmer AJ, Gibson OJ, Dudley C, Bryden K, Hayton PM, Tarassenko L, et al. A randomized controlled trial of the effect of real-time telemedicine support on glycemic control in young adults with type 1 diabetes (ISRCTN 46889446). Diabetes Care. 2005;28:2697-702.

33. Landau Z, Mazor-Aronovitch K, Boaz M, Blaychfeld-Magnazi M, Graph-Barel C, Levek-Motola N, et al. The effectiveness of Internet-based blood glucose monitoring system on improving diabetes control in adolescents with type 1 diabetes. Pediatr Diabetes. 2012;13:203-7.

34. Gay CL, Chapuis F, Bendelac N, Tixier F, Treppoz S, Nicolino M. Reinforced follow-up for children and adolescents with type 1 diabetes and inadequate glycaemic control: a randomized controlled trial intervention via the local pharmacist and telecare. Diabetes and Metabolism. 2006;32:159-65.

35. Esmatjes E, Jansa M, Roca D, Perez-Ferre N, del Valle L, Martinez-Hervas $S$, et al. The efficiency of telemedicine to optimize metabolic control in patients with type 1 diabetes mellitus: Telemed study. Diabetes Technol Ther. 2014;16:435-41.

36. Cook S, Herold K, Edidin DV, Briars R. Increasing problem solving in adolescents with type 1 diabetes: the choices diabetes program. Diabetes Educ. 2002:28:115-24

37. Howe CJ, Jawad AF, Tuttle AK, Moser JT, Preis C, Buzby M, et al. Education and telephone case management for children with type 1 diabetes: a randomized controlled trial. J Pediatr Nurs. 2005;20:83-9.

38. Nunn E, King B, Smart C, Anderson D. A randomized controlled trial of telephone calls to young patients with poorly controlled type 1 diabetes. Pediatr Diabetes. 2006;7:254-9.

39. Katz ML, Volkening LK, Butler DA, Anderson BJ, Laffel LM. Family-based psychoeducation and Care Ambassador intervention to improve glycemic control in youth with type 1 diabetes: a randomized trial. Pediatr Diabetes. 2014;15:142-50.

40. Hampson SE, Skinner TC, Hart J, Storey L, Gage H, Foxcroft D, et al. Effects of educational and psychosocial interventions for adolescents with diabetes mellitus: a systematic review. Health Technol Assess. 2001:5:1-79.

41. Dabelea D, Mayer-Davis EJ, Saydah S, Imperatore G, Linder B, Divers J, et al. Prevalence of type 1 and type 2 diabetes among children and adolescents from 2001 to 2009. JAMA. 2014;311:1778-86.

42. Patterson CC, Gyurus E, Rosenbauer J, Cinek O, Neu A, Schober E, et al. Trends in childhood type 1 diabetes incidence in Europe during 1989-2008: evidence of non-uniformity over time in rates of increase. Diabetologia. 2012;55:2142-7.

43. Cochrane Collaboration. Cochrane handbook for systematic reviews of interventions. 2009. Available at: www.cochrane-handbook.org. Accessed 10th Februaty 2016.

44. Liberati A, Altman DG, Tetzlaff J, Mulrow C, Gotzsche PC, loannidis JP, et al. The PRISMA statement for reporting systematic reviews and meta-analyses of studies that evaluate health care interventions: explanation and elaboration. J Clin Epidemiol. 2009;62:e1-34.

45. Franc S, Daoudi A, Mounier S, Boucherie B, Dardari D, Laroye H, et al. Telemedicine and diabetes: achievements and prospects. Diabetes Metab. 2011;37:463-76

46. Higgins JP, Altman DG, Gotzsche PC, Juni P, Moher D, Oxman AD, et al. The Cochrane Collaboration's tool for assessing risk of bias in randomized trials. BMJ. 2011;343:d5928.

47. Higgins JP, Thompson SG. Quantifying heterogeneity in a meta-analysis. Stat Med. 2002;21:1539-58. 
48. Burgess S, White IR, Resche-Rigon M, Wood AM. Combining multiple imputation and meta-analysis with individual participant data. Stat Med. 2013;32:4499-514.

49. Mendes AB, Fittipaldi JA, Neves RC, Chacra AR, Moreira Jr ED. Prevalence and correlates of inadequate glycaemic control: results from a nationwide survey in 6,671 adults with diabetes in Brazil. Acta Diabetol. 2010;47:137-45.

50. Gomes MB, Cobas RA, Matheus AS, Azevedo MJ. Regional differences in clinical care among patients with type 1 diabetes in Brazil: Brazilian Type 1 Diabetes Study Group. Diabetology \& Metabolic Syndrome. 2012;1:44.

51. Gomes MB, Coral M, Cobas RA, Dib SA, Canani LH, Nery M, et al. Prevalence of adults with type 1 diabetes who meet the goals of care in daily clinical practice: a nationwide multicenter study in Brazil. Diabetes Res Clin Pract. 2012;97:63-70

52. Viana LV, Leitão CB, Kramer CK, Zucatti ATN, Jezini DL, Felício J, Valverde $A B$, Chacra AR, Azevedo MJ, Gross JL. Unpublished data extracted from a Brazilian database from patients with diabetes attending the public healthcare system. 2013.

\section{Submit your next manuscript to BioMed Central} and we will help you at every step:

- We accept pre-submission inquiries

- Our selector tool helps you to find the most relevant journal

- We provide round the clock customer support

- Convenient online submission

- Thorough peer review

- Inclusion in PubMed and all major indexing services

- Maximum visibility for your research

Submit your manuscript at www.biomedcentral.com/submit 